\title{
DNA Barcoding Facilitates Bat Species Identification for Improved Surveillance of Bat-associated Rabies across Canada
}

\author{
Susan A. Nadin-Davis*,1, Erin Guerrero ${ }^{2}$, M. Kimberley Knowles ${ }^{1}$ and Yuqin Feng ${ }^{\sharp 1}$ \\ ${ }^{I}$ Centre of Expertise for Rabies, OIE Reference Laboratory for Rabies and WHO Collaborating Centre for Control, \\ Pathogenesis and Epidemiology of Rabies in Carnivores, Ottawa Laboratory (Fallowfield), Canadian Food Inspection \\ Agency, Ottawa, ON, Canada \\ ${ }^{2}$ Dept. of Biology, University of Ottawa, Ottawa, ON, Canada
}

\begin{abstract}
For many families within the animal kingdom, DNA barcoding has proven to be a valuable tool for confirmation of species identification and it will be increasingly used to identify the reservoir hosts of zoonotic diseases. Rabies is a fatal disease that can be transmitted to virtually all mammalian species but the etiological agent, rabies virus, is maintained in particular host reservoirs comprising various carnivore and chiropteran species. With the success of rabies control programs that target carnivores across the Americas and in Europe, chiropteran rabies cases worldwide will assume proportionately greater significance in the future. Information on the species of bats which act as rabies reservoirs and which are most likely to infect other mammals by spill-over transmission of the virus is important from public and veterinary health perspectives. While bats submitted for rabies diagnosis from across Canada are identified to species according to their morphological traits, accurate species assignment may often be compromised due to poor sample condition or submission of limited material. In this study, a collection of bats representative of the species most commonly submitted for rabies diagnosis, as identified by morphological examination of the specimens, was re-examined by DNA barcoding methods. This comparison identified certain species which are routinely misidentified by traditional taxonomic methods and suggests that species confirmation by barcoding will improve the epidemiological information generated from rabies testing.
\end{abstract}

Keywords: Bat species assignment, Chiroptera, DNA barcoding, Rabies.

\section{INTRODUCTION}

Interest in various aspects of bat biology and global recognition of bats as reservoirs for many infectious agents [1] are driving increased research on these mammals. Due to the challenges often posed in species identification through the use of traditional morphological-based taxonomy, application of genetic-based methods for species identification is increasingly popular. One of the best developed methods is DNA barcoding [2] in which nucleotide sequencing of a portion of the mitochondrial cytochrome $\mathrm{c}$ oxidase subunit 1 (COX1) gene, followed by phylogenetic comparison with reference sequences in the barcode of life database (BOLD), can assign a specimen to species. Such studies have facilitated identification of cryptic species [3] and have increased awareness of species diversity within the Chiroptera $[4,5]$.

Rabies is caused by members of the lyssavirus genus [see 6], bullet-shaped viruses with a non-segmented negative sense RNA genome of about $12 \mathrm{~Kb}$ that encodes five genes [7]. Unlike the lyssaviruses associated with chiropteran

\footnotetext{
*Address correspondence to this author at the Ottawa Laboratory (Fallowfield), Canadian Food Inspection Agency, 3851 Fallowfield Rd., Ottawa, ON, Canada K2J 4S1; Tel: 1613228 6698; Ext: 5900;

Fax: 1613228 6669; E-mail: Susan.Nadin-Davis@inspection.gc.ca

${ }^{\#}$ Current address: Centre of Expertise for Transmissible Spongiform Encephalopathies, Ottawa Laboratory (Fallowfield), Canadian Food Inspection Agency, Ottawa, ON, Canada
}

species in many parts of the world, those of the American continent belong to the prototype rabies virus species $[8,9$, 10]. In North America the rabies virus is also maintained by many other wildlife reservoirs including foxes, skunks and raccoons [11]. Various approaches to control and eliminate rabies from terrestrial species, including various vaccination strategies and selective depopulation, have been quite successful in certain jurisdictions [12, 13]. Similarly, the success of dog vaccination programs in Latin America has significantly reduced cases in this host with concomitant reductions in human case numbers [14]. In contrast the size, sheer numbers, feeding habits and aerial life-style of chiropteran species pose special challenges to bat rabies control strategies [15]. Efforts to control vampire bat populations using anticoagulants [16] or to establish the utility of oral vaccines in these hosts $[17,18]$ have yet to be developed into logistically feasible methods for vampire bat rabies control. Strategies to control rabies in insectivorous bats have not yet been conceived.

The net effect of these species-targeted interventions is that bat rabies may assume increasing importance as a major rabies threat in the future. A number of human deaths caused by infection with bat-associated rabies viruses have been reported in both the US [19] and Canada [20, 21]. Frequently the general public does not recognize bat contact as a potential exposure to the disease and in some cases the victim may 
be unaware of superficial bat bites. Recently vampire bat rabies has caused several human deaths in remote Amazon regions of Brazil [22]. Spill-over of bat rabies to domestic animals is also of concern, particularly in areas where high costs preclude vaccinating large numbers of animals (e.g., bovines in Latin America) or where rabies is considered a limited threat due to the absence of other terrestrial sources (e.g. maritime provinces of Canada). The recent initiation of a new epizootic in skunks in Arizona by a variant of the big brown bat rabies virus [23] raises concerns that other similar events could undermine rabies control efforts in terrestrial species.

Since the initial identification of bat rabies in North America in the 1950s [reviewed in 24], increased surveillance has identified bat rabies in most US states and in all Canadian provinces with hundreds of cases reported annually. Of the 39 species of bats considered indigenous to North America north of Mexico, 30 have been reported positive for rabies by the late 1970s [25]. In Canada and the northern United States the Big brown bat (Eptesicus fuscus) is the species most commonly diagnosed with rabies [26, 27] but in the southern United States other species such as the Red bat (Lasiurus borealis) and the Brazilian free-tailed bat (Tadarida brasiliensis) are important rabies vectors [28, 29]. Other bat species that are less frequently diagnosed include the Silver-haired bat (Lasionycteris noctivagans), several members of the Myotis genus, the Eastern pipistrelle (Pipistrellus subflavus), Western pipistrelle (P. hesperus) and other lasiurine bats such as the Hoary bat ( $L$. cinereus) and Yellow bat (L. seminolus) [30, 31]. In Canada only 19 bat species have been recorded and just 17 are considered indigenous [32] as listed in the methods section below. Not all species are considered to be rabies reservoirs; indeed the rarer species are probably too small in numbers to maintain a disease such as rabies.

Generally each bat reservoir species harbours a distinct viral variant [33, 34], except for the bats of the Myotis genus which harbour a distinct but heterogeneous group of viruses and Big brown bats which harbour several viral variants comprising multiple lineages with distinct geographical ranges $[35,36]$. The host species for some rarely isolated variants remain unknown [37] and future identification of additional bat rabies reservoirs is likely. Knowledge of bat rabies epidemiology clearly depends on accurate assignment to species for all rabies-positive bat cases. When specimens are in poor condition (e.g. desiccated, mutilated), or when only a limited portion of the specimen is submitted, accurate species assignment by its morphology alone may be difficult or even impossible and alternative methods of species identification are needed. This study has explored whether the use of genetic barcoding tools significantly improves the accuracy of species assignment for bat specimens submitted for rabies diagnosis in Canada. It was discovered that certain Myotis species were misidentified to a very significant degree when only their morphological traits were considered. This study emphasizes the value of genetic confirmation of the species identity of all rabies-positive bat specimens so as to better understand their spatial distribution and range of the rabies virus variants they harbour across Canada.

\section{MATERIALS AND METHODOLOGY}

\section{Bat Specimens}

All specimens employed in this study were obtained from rabies diagnostic submissions sent to the two CFIA laboratories, in Ottawa, Ontario, and Lethbridge, Alberta, that are responsible for rabies diagnosis across Canada. Specimens received over a period of several years (from 1997-2007) were included though most specimens were recovered from 2004 onwards. Approximately $75 \%$ of all submissions came from Ontario and Quebec, $15 \%$ were from the province of British Colombia and the remaining 10\% came from all other provinces and territories. Except for rarer species for which numbers were limited, at least twelve specimens from across the range of each species were selected for study.

Specimens were first examined by laboratory diagnostic staff and assigned to species based on specific morphological keys as described by the National Audubon Society [38] and Nagorsen [39] and with reference to other on-line sources of information [40, 41]. Brain tissue impressions were tested for rabies by the standard direct fluorescent antibody test [42]. While the majority of samples included in this study were rabies negative, they included representatives of all species known or suspected to act as rabies hosts. Bat carcasses were preserved at $-80^{\circ} \mathrm{C}$ to allow subsequent reexamination for confirmation of species assignment by experts in bat taxonomy. Specimens of this study have been designated as follows: a two digit number indicating year of submission, a two letter code representing the province of origin, a four or five digit specimen identifier followed by a two letter suffix to indicate the assigned species thus: BB, Big brown bat (Eptesicus fuscus); CL, California bat (Myotis californicus); EP, Eastern pipistrelle (Pipistrellis subflavus); FR, Fringed bat (Myotis thysanodes); HR, Hoary bat (Lasiurus cinereus); KE, Keen's bat (Myotis keenii); LB, Little brown bat (Myotis lucifugus); LE, Long-eared bat (Myotis evotis); LL, Long-legged bat (Myotis volans); NL, Northern long-eared bat (Myotis septentrionalis); RE, Red bat (Lasiurus borealis); SH, Silver-haired bat (Lasionycteris noctivagans); WE, Western long-eared bat (Corynorhinus townsendii); WS, Western small-footed bat (Myotis ciliolabrum); YU, Yuma bat (Myotis yumanensis). Species not represented in our collection include the Spotted bat (Euderma maculatum), the Western red bat (L. blossevilli), the Eastern small footed bat (Myotis leibii) and the Pallid bat (Antrozous pallidus). For ease of comparison all species designations follow those employed in BOLD at time of manuscript preparation though it is recognised that the classification of Pipistrellus has been revised.

\section{DNA Extraction and COX1 Amplification}

DNA was recovered from approximately $50 \mathrm{mg}$ of bat brain, lung or spleen tissue or from a few tufts of fur by grinding in a hexadecyl trimethyl ammonium bromide (Sigma-Aldrich, Oakville, ON) solution followed by phase separation with the addition of chloroform and alcohol precipitation as described previously [43]. The final dried DNA pellet was dissolved in TLE buffer $(10 \mathrm{mM}$ Tris- $\mathrm{HCl}, \mathrm{pH}$ 8.0, $0.1 \mathrm{mM}$ EDTA) and stored at $-20^{\circ} \mathrm{C}$. Nucleic acid concentration was determined spectrophotometrically. 
Total DNA was used as template for amplification of a 5, proximal region of the mitochondrial $\mathrm{COX} 1$ gene. Initial trials employed primer pair COX-F2/COX-R1 (Table 1) which had previously proven successful in generating a 707 bp amplicon from Big brown bats [36].

However, this primer pair did not consistently amplify the COX1 amplicon from all species and several additional primers were designed and tested. Details of the primers used for successful COX1 gene amplification of bat species are provided in Tables $\mathbf{1}$ and $\mathbf{2}$ and their relative positions within the COX1 open reading frame (ORF) are illustrated (Fig. 1).

Amplification was performed in a $50 \mu 1$ reaction containing 1x PCR buffer (Invitrogen, Burlington, ON), $1.5 \mathrm{mM}$ $\mathrm{MgCl}_{2}, 0.2 \mathrm{mM}$ dNTPs and 2.5 units Taq DNA polymerase (Invitrogen). For the F2/R1 primer pair the thermocycling profile employed was $94^{\circ} \mathrm{C}, 4 \mathrm{~min}$ followed by 30 to $40 \mathrm{cy}-$ cles of $94^{\circ} \mathrm{C}$ for $30 \mathrm{sec}, 50^{\circ} \mathrm{C}$ for $35 \mathrm{sec}, 72^{\circ} \mathrm{C}$ for $1.5 \mathrm{~min}$, and a final elongation at $72^{\circ} \mathrm{C}$ for 5 to $7 \mathrm{~min}$. Cycling with the other primer pairs was similar except that the annealing

Table 1. Summary of Primers Employed for COX1 Amplification

\begin{tabular}{|l|l|l|l|}
\hline \multicolumn{1}{|c|}{ Primer Name } & \multicolumn{1}{|c|}{ Tm $\left({ }^{\circ} \mathbf{C}\right)$} & \multicolumn{1}{|c|}{${\text { Primer Sequence 5' } \rightarrow \mathbf{3}^{\prime}}^{\text {Location in Human Mitochondrial Genome }}$} \\
\hline \hline COX-F2 & 60.2 & TCAACCAACCACAAAGACATTGGCAC & $5928-5953$ \\
\hline COX-F4 & 53.6 & TCAACCAATCAYAAAGAYATTGGTAC & $5928-5953$ \\
\hline COX-F6 & 57.9 & TATYTACTATTTGGYGCTTGAGC & $5958-5980$ \\
\hline & & & \\
\hline COX-R1 & 59.8 & TAGACTTCTGGGTGGCCAAAGAATCA & $6634-6609$ \\
\hline COX-R4 & 57.5 & GTGAAYATATGGTGGGCTCATACGAT & $6784-6759$ \\
\hline COX-R5 & 52.3 & CCAAAGAATCARAAYAAGTGTTGATAT & $6619-6593$ \\
\hline COX-R7 & 60.2 & CGGTCTGTTATTAGTATTGTAATACC & $6541-6516$ \\
\hline
\end{tabular}

${ }^{a}$ based on Genbank Accession number NC_012920.

Table 2. Optimal Primer Pairs Employed for COX1 Amplification

\begin{tabular}{|c|c|c|}
\hline Primer Pair & Species Amplified $^{1}$ & Amplicon Size (bp) \\
\hline COX-F4 / COX-R4 & HR, SH, WE & 857 \\
\hline COX-F4 / COX-R5 & CL & 692 \\
\hline
\end{tabular}

${ }^{1}$ Bat species are indicated by their two letter abbreviations as defined in Materials and Methodology.

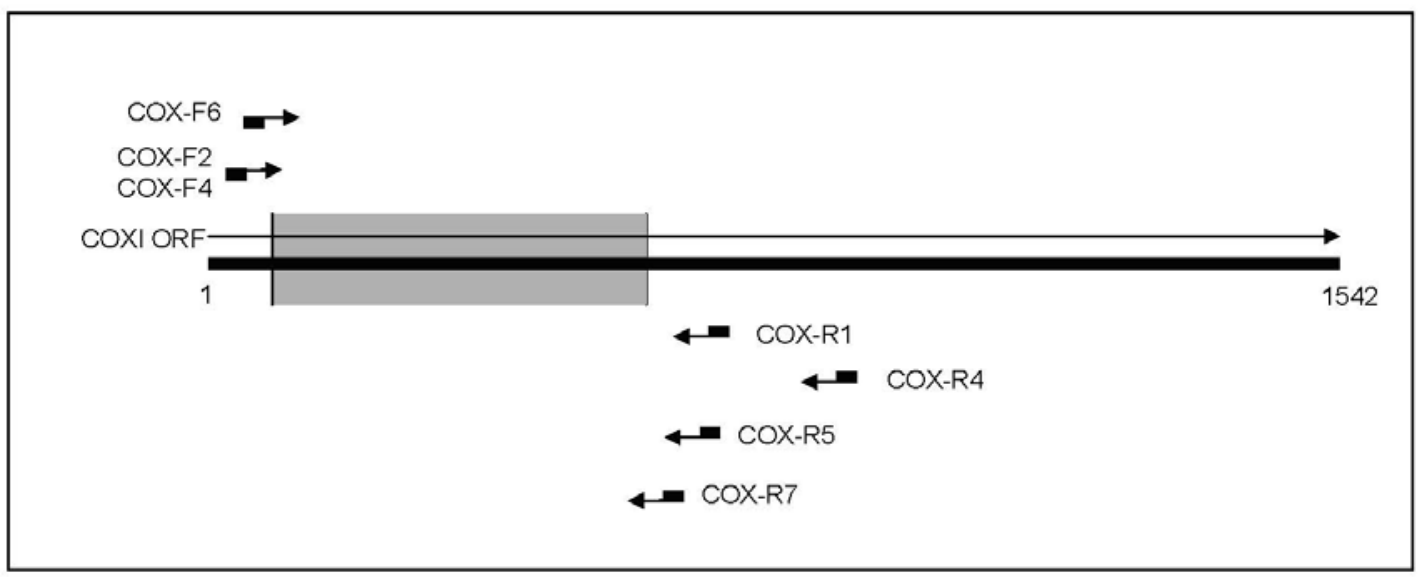

Fig. (1). Diagram illustrating the relative positions and orientation of the PCR primers along the length of the COX1 open reading frame. Primer target sites are indicated by the rectangles and arrows indicate the direction of extension. The greyed area shows the region targeted for nucleotide sequencing. 
temperature was reduced to $45^{\circ} \mathrm{C}$ or $42^{\circ} \mathrm{C}$ for the $\mathrm{COX}$ F6/COX-R7 primer combination. Amplicon production was examined by electrophoresis of reaction aliquots through $1 \%$ agarose gels and amplicons were purified directly using a Wizard PCR Preps purification kit (Promega, Madison, WI) as recommended by the manufacturer.

\section{Sequencing and Phylogenetic Analysis}

Sequencing reactions were performed on both strands of the PCR product using a Thermosequenase ${ }^{\mathrm{TM}}$ kit (GE Healthcare, Baie d'Urfé, QC) and IR-dye labelled versions of the COX1 PCR primers. Products were resolved on a NEN 4200L automated system (LiCor, Lincoln, NE) and ESeq ver. 3 software (LiCor) was used for base calling and manual editing. Complementary sequence reads were combined using AlignIR software (LiCor) and multiple sequence alignments were performed with CLUSTAL-X [44]. The entire dataset was trimmed to a length of 516 bases (corresponding to positions 6000 to 6515 of the human mitochondrial genome, GenBank Accession number NC_012920). The partial COX1 gene sequences described in this report have been deposited to GenBank and assigned accession numbers HM486527 to HM486678.

Genetic distance values were determined using MEGA 4 software [45] with the Kimura 2 parameter substitution model. Phylogenetic analysis was performed with PHYLIP ver. 3.63 [46] using the neighbour joining (NJ) method and by PhyML ver. 3 [47] to generate a maximum likelihood (ML) tree using the optimum substitution model as determined with Modeltest ver. 3.7 [48]. Translation of nucleotide sequences to protein was performed using BioEdit ver. 7.0.5 [49].

\section{Species Confirmation Via Barcoding}

Selected sequences representative of the genetic diversity of each clade were submitted for species assignment to the BOLD [50].

\section{RESULTS}

\section{Proportion of Rabies Positive Cases in Bat Hosts}

Records of all rabies positive cases identified in Canada on an annual basis through a passive surveillance system over a 12-year period were divided into those found in bats and those due to all other terrestrial species. These data (Fig. 2) show a generally decreasing trend for rabies cases in terrestrial species but a reasonably constant number of cases in bats (mean $=80$ bat cases annually). The percentage of cases in bats compared to cases in all species has varied from $8.4 \%$ to $43.4 \%$ and was $37.9 \%$ in 2009 , indicative of an overall increasing proportion of bat-associated cases. These data underlie the need for enhanced efforts to better understand the epidemiology of rabies in the order Chiroptera.

\section{COX1 Tree and Clade Assignment to Species}

COX1 amplification and sequencing was performed using DNA from a collection of 260 bat specimens, including 108 Big brown bat (BB) samples described previously [36]. For comparative purposes only 28 representative specimens of the BB group are included in the NJ tree presented in Fig. 3. This tree groups 180 chiropteran $\mathrm{COX} 1$ sequences into 13 distinct clades, each of which was tentatively assigned to species based on specimen morphology. To confirm that the clades generated through the barcoding analysis had been correctly assigned to species, several sequences (indicated by an asterisk in Fig. 3) representative of the genetic diversity of each clade were submitted to the BOLD for species assignment (Table 3).

Members of subgroup A of the BB clade were similar (100\% identity) to Big brown bat records within the BOLD whereas a subgroup B specimen exhibited only $92.72 \%$ identity with this species, perhaps because of a lack of submissions to the BOLD from British Columbia. Correct assignment of groups CL, EP, HR, LB, LL, NL, RE and SH was strongly supported with identity values to the presumed species > 99\% whereas the LE group exhibited reasonably

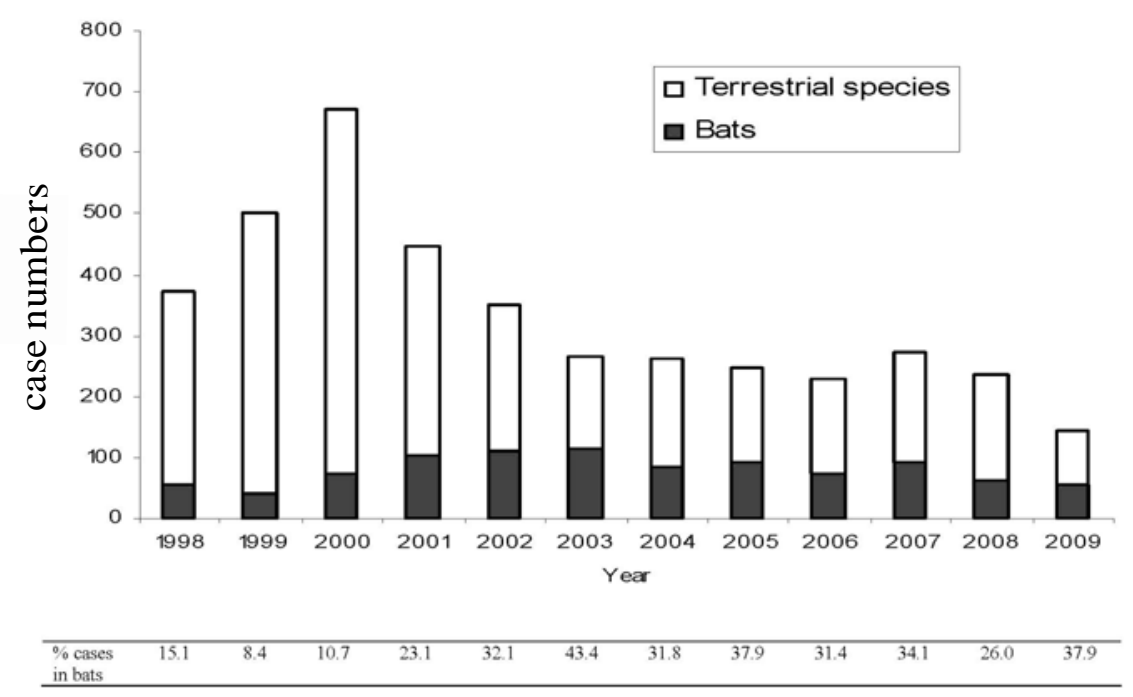

Fig. (2). Bar chart showing the total number of rabies positive cases in terrestrial and chiropteran species reported per year in Canada (19982009). The percentage of all positive cases reported in bat species is indicated below the graph. Data is taken from the information posted on the CFIA website (http://www.inspection.gc.ca/english/anima/disemala/rabrag/statse.shtml). 


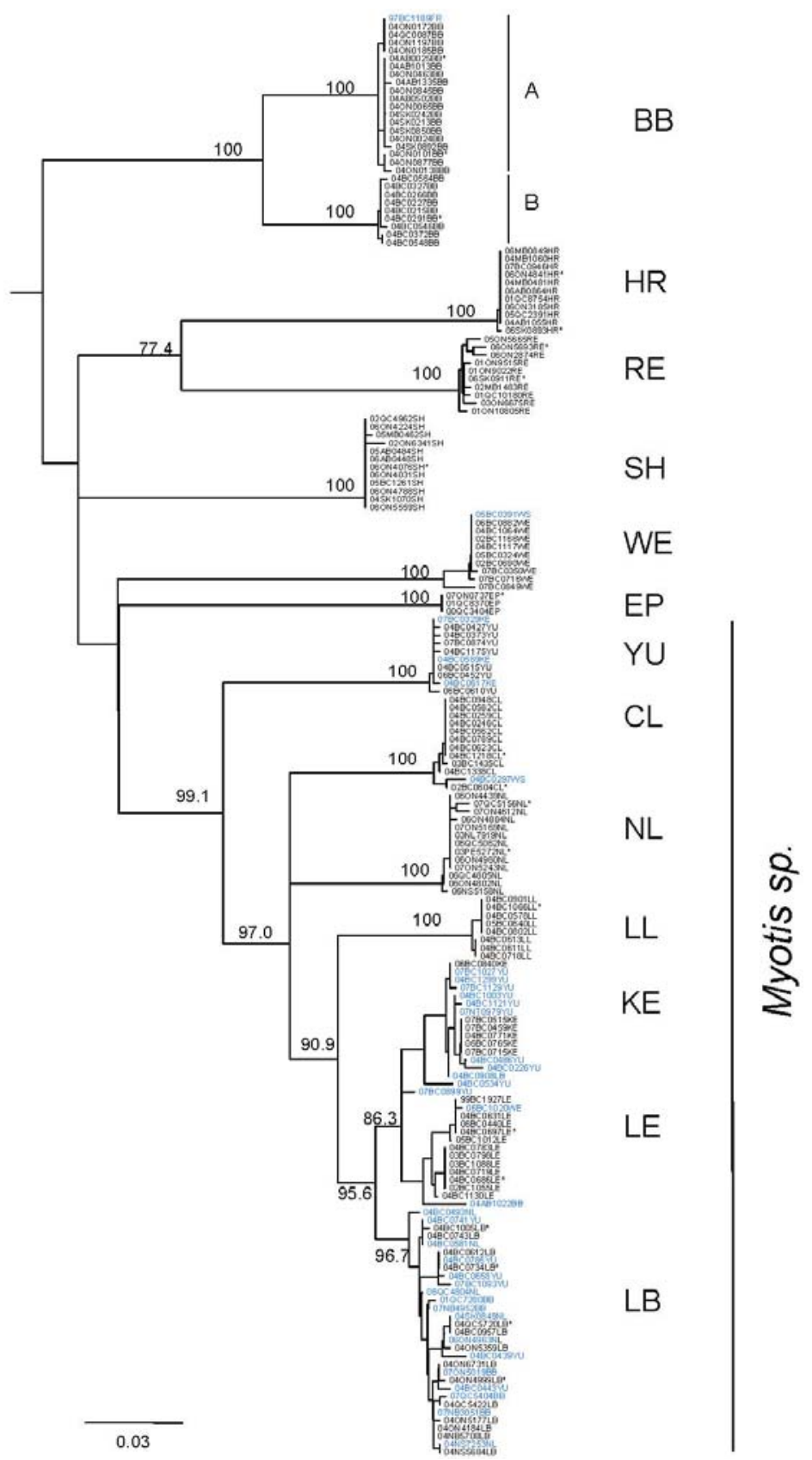

Fig. (3). NJ tree of 180 bat COX1 sequences. A NJ analysis employing a 516 nucleotide segment of the COX1 gene was generated using the human sequence as outgroup. Branch lengths represent distances as indicated by the scale at bottom left and bootstrap values $>70 \%$ are shown above each branch. Clades are assigned to species as indicated to the right by a two letter code as defined in the Materials and Methodogy. Sequences used for species confirmation by comparison with the BOLD are indicated by "*” whereas specimens that cluster in the wrong clade based on their morphological classification are identified in blue after their designation.

strong identities (>97\%) to Long-eared bat specimens in the database. Similarly the two members of the WE group submitted for comparison exhibited between 97.86 to $99.25 \%$ identity to Corynorhinus townsendii townsendii specimens in BOLD. Analysis of the YU and KE clades was less clear-cut. A single $M$. evotis sequence gave the best match to the two YU samples examined (04BC0515YU and 06BC0610YU) at $>99 \%$ and matches of $99.1 \%$ and $98.8 \%$ respectively to specimens of $M$. yumanensis saturatus. A rather similar situation existed for the $\mathrm{KE}$ clade. Two KE samples (06BC0840KE and 07BC0715KE) matched to a single Little brown bat specimen in BOLD with $99.5 \%$ and $99.7 \%$ similarity respectively but matches with all other Little brown bat specimens were significantly lower at $\leq 96.6 \%$. M. keenii samples in BOLD matched these two samples with $97.2 \%$ and $96.7 \%$ respectively. Despite these rather ambiguous results, based on the respective phylogenetic locations of the $\mathrm{KE}$ and YU groups we believe that these species are correctly assigned.

Most bat specimens which had been assigned to the same species by their morphological traits, as indicated by their 
Table 3. Intra-clade Genetic Distances of All Bat Groupings ${ }^{1}$ and Identity Match of Selected Specimens to Samples in the BOLD

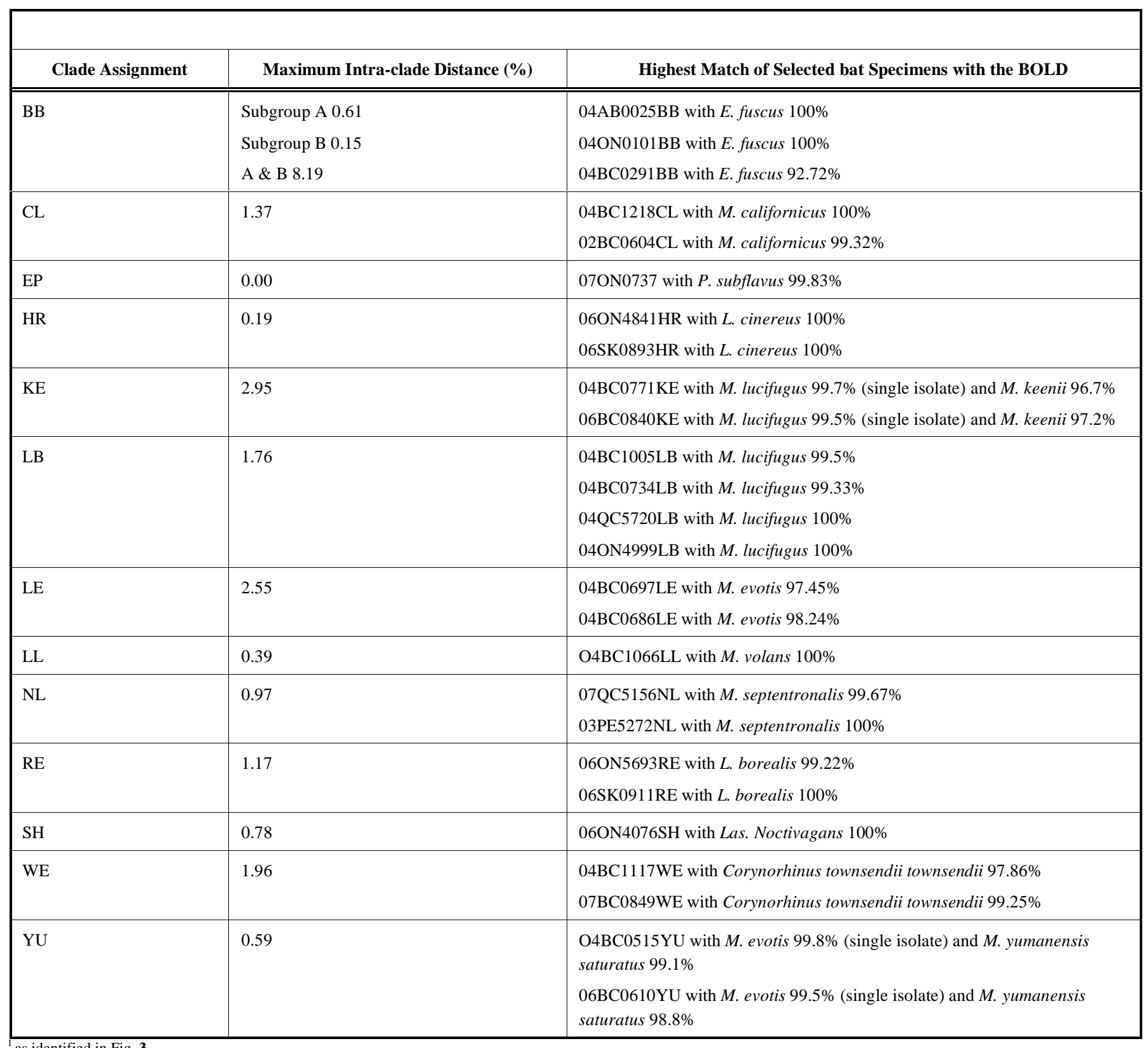

two letter suffix designation, clustered together by phylogenetic analysis, thus suggesting a good concordance of species assignment by both methods. In only one instance did a specimen (07L0899YU) fail to cluster within a discrete group thereby making its species assignment by barcoding ambiguous (lies between LE and KE clades). Some notable discrepancies between the two classification schemes included the specimen originally identified as a fringed bat (97BC1189FR) that clustered with the big brown bat clade and specimen 05BC0391WS that clustered with the WE group. The remaining discrepancies occurred within the Myotis genus clades, some of which, particularly those of the YU, KE and LB groups, contained specimens with mixed species assignments as determined by their morphological traits. Assuming the greater accuracy of the genetic barcod- ing technique, Table 4 summarises the rate of successful species assignment based on morphology only. These data clearly illustrate that discrimination among certain species of Myotis by this approach is problematic. Subsequent careful review of many of the carcasses suggested that indeed the original morphological assessments had been in error.

For most groupings intra-clade genetic diversity is relatively limited (see Table 3). The exception is the BB group that, as identified previously [36], is divided into two genetically distinct subgroups; in this study these had intrasubgroup genetic distance ranges of $0-0.614 \%$ (subgroup A) and $0-0.153 \%$ (subgroup B) and inter-subgroup distances ranging between $7.842-8.185 \%$. All other clades exhibited < $2 \%$ intra-clade genetic distance except for the KE and LE groups for which maximum distance values were higher. For 
Table 4. Success Rate of Bat Species Identification by Traditional Taxonomy in Comparison with DNA Barcoding

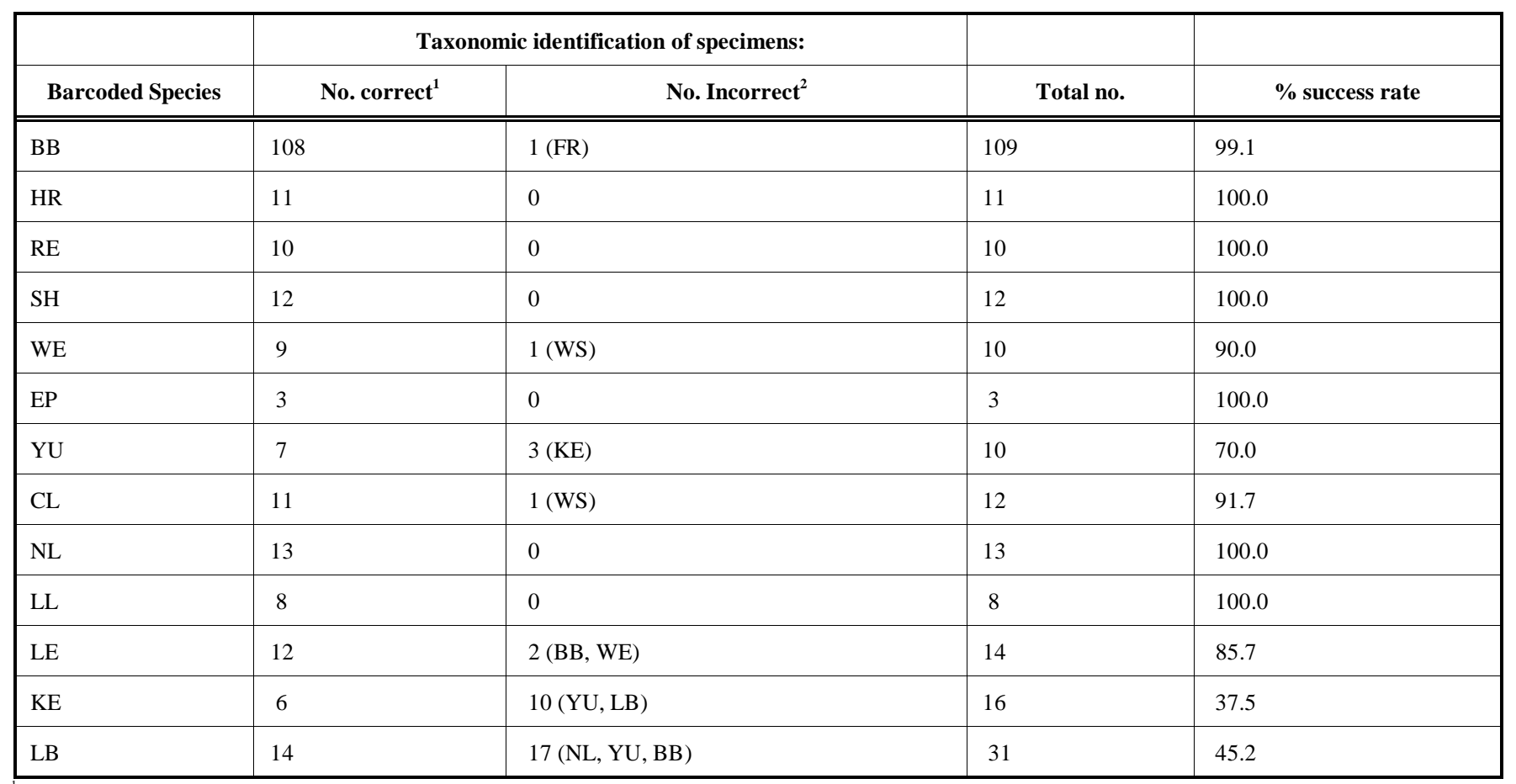

${ }^{1}$ Number of specimens for which species identification by morphology and barcoding agree

${ }^{2}$ Number of specimens for which species identification by morphology does not agree with the barcoding assignment. The incorrectly assigned species is shown in brackets.

the KE clade, exclusion of an outlying specimen (04BC0534YU) reduced the maximum intra-clade distance to $1.56 \%$. It is also notable that specimen 07L0899YU lies between the KE and LE clades and is not included in either group. When all 13 clades were considered, average interspecies distance values ranged between $3.51 \%$ (KE and LE groups) to $26.97 \%$ (LL and HR groups).

Since it was recently suggested that ML methods are superior for analysis of barcoding data [51], the dataset was reanalysed by ML methods. Modeltest identified the $\mathrm{TrN}+\mathrm{I}+\mathrm{G}$ substitution model, in which I is the proportion of invariable sites and $\mathrm{G}$ is the gamma shape distribution parameter of the variable sites, as the best fit to the data based on its log likelihood value $(-\operatorname{lnL}=3977.45)$. However, the more generally applicable $\mathrm{HKY}+\mathrm{I}+\mathrm{G}$ model, ranked a close $3^{\text {rd }}$ by the Modeltest analysis $(-\ln L=3979.62)$, was convenient for ML analysis using the calculated values of $\mathrm{I}=0.549$ and $\mathrm{G}=1.0906$. The resulting $\mathrm{ML}$ tree (Fig. 4) exhibits a very similar topology to the NJ tree and provides strong bootstrap support for most clades with the exception of the LB, KE and LE clades for which values were low $(<60 \%)$. Sample 04BC0493NL did not associate with any of these clades (identified as LB by $\mathrm{NJ}$ ) whereas 07BC0899YU was grouped as an outlier of the KE group with very poor $(35 \%)$ bootstrap support.

Review of the nucleotide alignment indicated that many of the nucleotide substitutions identified were specific to one or more clades, i.e., they respected the phylogenetic profile of the dataset. The overall transition/transversion ratio for the database was 5.039 indicating a significant bias towards more conservative coding changes. Indeed, despite the significant nucleotide variation within this dataset the predicted amino acid sequences were remarkably conserved. Over the 172 residue length of the translated region (with residue 1 being equivalent to residue 33 of the human $\mathrm{COX} 1$ product) the 180 bat specimens exhibited replacements at just 15 sites of which only four were strictly conserved within one or more groups. The WE samples accounted for three of these changes and involved two relatively conservative replacements: $\mathrm{I}$ in place of $\mathrm{V}$ at residue 51 and $\mathrm{V}$ in place of $\mathrm{I}$ at residue 137 as well as a less conservative change involving replacement of $\mathrm{M}$ with $\mathrm{T}$ at residue 85 . A substitution of $\mathrm{T}$ in place of A was noted at residue 114 for BB, EP, RE, HR and $\mathrm{SH}$ specimens. All other amino acid replacements were single site changes scattered throughout the sequence usually within single isolates.

\section{DISCUSSION AND CONCLUSION}

Genetic methods of species identification are increasingly used to improve epidemiological information on the role of certain species in harbouring diseases such as rabies. In the United Kingdom, both a mitochondrial marker, cytochrome b (cyt b) and the nuclear $\beta$-actin gene have been used to identify bats harbouring European bat lyssavirus type 2 (EBLV-2) [52]. In Brazil, mammalian species carrying infectious diseases such as rabies have been identified using the mitochondrial control region [53]. Since the Canadian DNA barcoding initiative is now being adopted globally to explore species diversity [54], our study has explored the utility of this approach for confirming the species of Canadian bats that are submitted for rabies diagnosis.

From the barcoding collection of Canadian bats available, our study included 13 confirmed species but lacked information on the following rare species: the Pallid bat ( $\mathrm{An}$ - 


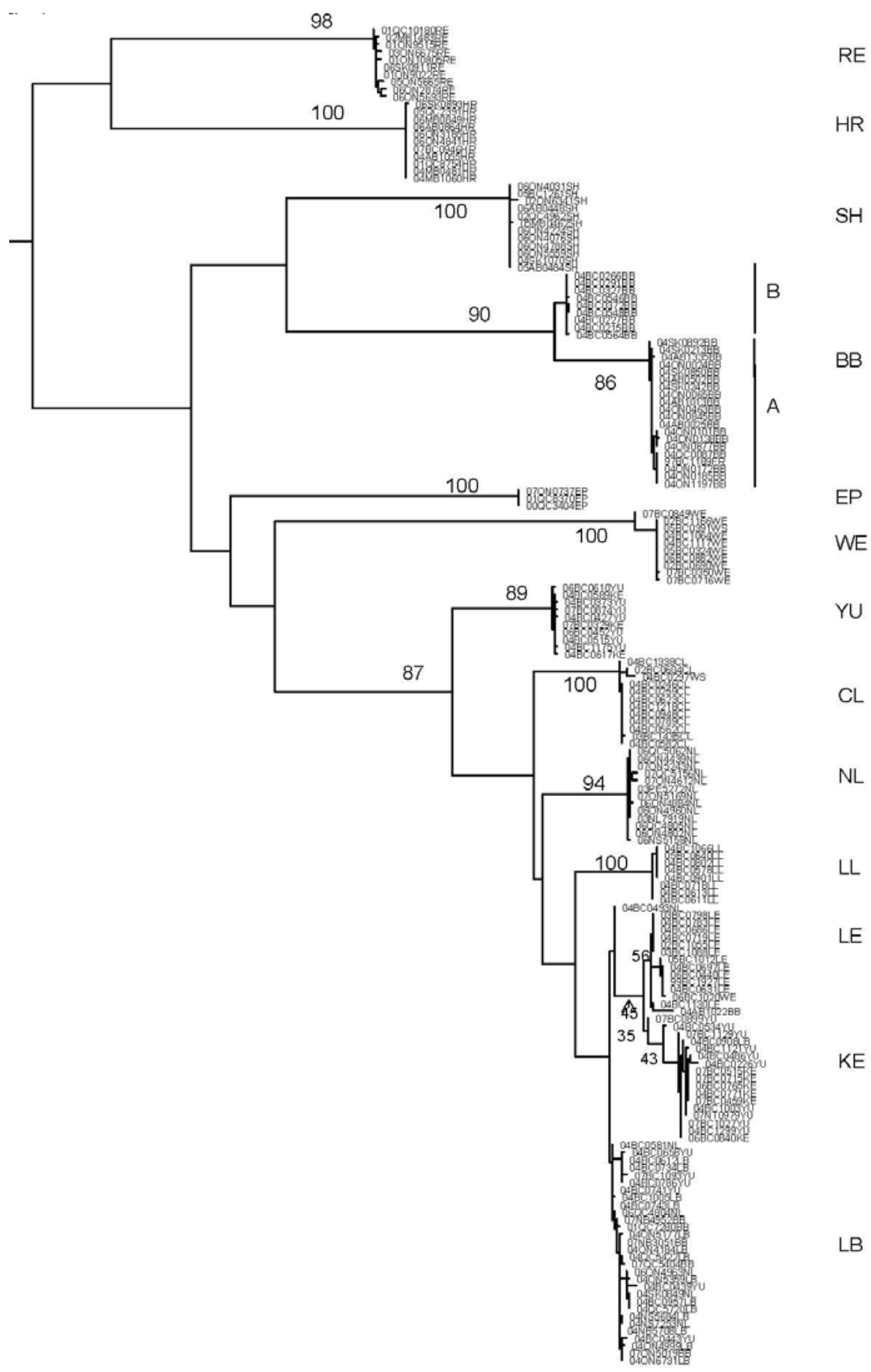

Fig. (4). Phylogeny of 180 bat specimens as determined by a maximum likelihood analysis employing a 516 nucleotide segment of the COX1 gene. The human COX1 gene sequence was used as outgroup. Bootstrap values for main clades are shown above or below each branch.

trozous pallidus), Spotted bat (Euderma maculatum), Western red bat ( $L$. blossevilli), Eastern small-footed bat $(M$. leibii), Fringed bat (M. thysanodes) and the Western smallfooted bat (M. ciliolabrum). Specimens initially identified morphologically as members of the last two species were included in our analyses but barcoding identified them as belonging to other species. Several of these species are highly restricted to very limited ranges within Canada, are rarely encountered by humans and thus hardly ever submitted for rabies testing. Indeed the Pallid bat is a threatened species whereas the Spotted, Fringed and Keen's bats are listed as being of "special concern" under the Canadian Species at Risk Act [55]. While it is unlikely that these rarer bat species are important rabies reservoirs in Canada, future disease incursions into these species could have catastrophic implications for these limited populations.

During the conclusion of our study, Streicker et al., [56] published a report describing bat rabies virus variants circulating in the US and included barcoding sequence informa- 
tion for many of their samples. Species that were represented included the Pallid bat (two samples), Western red bat (2 samples) and the Fringed bat (one sample). Incorporation of these sequences into our phylogenetic analysis (data not shown) yielded the following observations: (i) the Pallid bat sequences formed a separate clade that branched outside of the Myotis cluster, (ii) The Western red bat samples (together with one vouchered specimen from the Royal Ontario Museum, Toronto) clustered as an outlying group to our red bat clade, thereby reaffirming the distinctness of these two species, and (iii) the single Fringed bat clustered within our LE clade, raising questions about the identification of this specimen.

As of December 21, 2010, the BOLD contained barcode sequences for 624 species in the order Chiroptera and all bats indigenous to Canada were included in this list apart from the rare M. leibii (eastern small-footed bat). While species assignment of several of the phylogenetic groups identified by our analysis was readily confirmed by comparison with data in the BOLD, certain clades, especially the YU and KE groups, proved more difficult. Based on the respective locations of the KE and YU groups within our bat phylogeny their assignment to the Keen's and Yuma bat species respectively is in accord with previous phylogenetic analyses of these species using the mitochondrial cyt b locus [57] which recognised the Yuma bat as the more divergent of the Myotis genus and placed Keen's bats in close association with the Little brown bat. Furthermore a selection of three of the Yuma bat Cox 1 sequences recently reported by Streicker $e t$ al. [56] all clustered with the clade we had assigned to this species (data not shown). This is in contrast to the high identity for our YU samples to a single $M$. evotis sequence within BOLD and we suspect that this individual $M$. evotis specimen might be misidentified. Similarly, the close match of a single Little brown bat specimen in BOLD to the group identified here as Keen's bats may indicate misidentification of that Little brown bat specimen since all other specimens of that species exhibited $<96.7 \%$ similarity to our Keen's bat group; the second best match to our KE specimens within BOLD was provided by a $M$. keenii sequence $(96.7-97.2 \%$ identity). These observations underscore the need for careful evaluation and review of all sequence data and specimens submitted to the BOLD.

The intra-group genetic distance values observed for most groupings within our phylogeny are in most cases < $2 \%$, a value consistent with the general barcoding observation that interspecies variation at this locus is $>2 \%$ [2]. The high overall intra-group distance values $(>2 \%)$ for the $\mathrm{KE}$ and LE groups made differentiation between these two groups more challenging. A single isolate, originally assigned as a Yuma bat, placed between these two clades in the NJ tree whereas it was identified, with low confidence, as an outlier of the KE clade in the ML tree. The relatively small variation at the COX1 locus between certain species within the Myotis genus appears to be a limitation of the barcoding strategy that makes unequivocal differentiation of certain members of this genus challenging. Unfortunately these same species tend to be those most difficult to differentiate morphologically. To address such limitations it has been suggested that in some cases unequivocal species assignment may require the use of more than one locus, e.g., COX1 and either another mitochondrial marker such as the cyt $\mathrm{b}$ gene as employed in Europe or a nuclear marker [51]. A recent comparison of the use of cyt $b$ and COX1 for mammalian species assignment found that the former generally performed better and yielded higher inter-species resolution [58] so further evaluation of the cyt b locus for discrimination of North American Myotis species may prove useful. Indeed the complexity of barcode analysis for certain Myotis bat species has resulted in the use of the term "Myotis complex" to describe some members of this genus [56].

The large genetic distance observed between the two BB groups may suggest their assignment to two distinct subspecies. The restricted range (British Columbia) of BB subgroup $\mathrm{B}$ corresponds to the range proposed for the subspecies $E$. fuscus bernardinus whereas subgroup A specimens, from all other regions of Canada, corresponded to the ranges of two other subspecies, E. fuscus pallidus and E. fuscus fuscus which occupy the prairie provinces and eastern Canada respectively [59]. Re-evaluation of the subspecies structure of the Big brown bat populations of Canada and the US may be warranted given this new genetic information.

As illustrated in Table $\mathbf{4}$ accurate identification of several of the Myotis species is not achieved by morphological analysis alone. The bats recovered in British Columbia pose by far the greatest challenges due to the diversity of species with relatively similar physical traits that reside within this province. This fact and other factors, including poor sample integrity, difficulties in distinguishing between juveniles versus adults and limited time available for specimen examination in busy diagnostic laboratories, likely account for the majority of misidentifications.

In Canada, while specific rabies viruses are known to associate with particular bat species a group of heterogeneous viruses is associated with bats of the Myotis genus. Without accurate species identification of these bats, associating certain viral variants with particular species is clearly problematic. It is therefore suggested that the species of all rabies-positive bats, especially those of the Myotis genus, is confirmed by genetic characterisation so as to better establish their reservoir role. Indeed the Yuma bat has been identified as a distinct rabies reservoir host in the US [56] so it is of some interest to determine its status in Canada.

To streamline species assignment using genetic-based information, alternate methods such as use of microarrays in place of nucleotide sequencing have been shown to be feasible [60]. We propose to use the information generated in this study and available through BOLD to develop appropriate microarrays for Canadian bat species identification. In the future as barcoding information for bat species improves, similar approaches might be considered in other jurisdictions, particularly in the US and Latin American countries where the diversity of bat species and their rabies viruses is much larger [61, 62]. Improved understanding of the role of certain bat species in harbouring rabies is a necessary prerequisite for minimizing the public health effects of this disease. 


\section{ABBREVIATIONS}

$\begin{array}{llll}\mathrm{BOLD} & = & \text { Barcode of Life Database } \\ \mathrm{BB} & = & \text { Big brown bat } \\ \mathrm{CL} & = & \text { California bat } \\ \mathrm{EP} & = & \text { Eastern pipistrelle; } \\ \mathrm{FR} & = & \text { Fringed bat } \\ \mathrm{HR} & = & \text { Hoary bat } \\ \mathrm{KE} & = & \text { Keen's bat } \\ \mathrm{LB} & = & \text { Little brown bat } \\ \mathrm{LE} & = & \text { Long-eared bat } \\ \mathrm{LL} & = & \text { Long-legged bat } \\ \mathrm{NJ} & = & \text { neighbour-joining } \\ \mathrm{NL} & = & \text { Northern long-eared bat } \\ \mathrm{ML} & = & \text { maximum likelihood } \\ \mathrm{RE} & = & \text { Red bat } \\ \mathrm{SH} & = & \text { Silver-haired bat } \\ \mathrm{WE} & = & \text { Western long-eared bat } \\ \mathrm{WS} & = & \text { Western small-footed bat } \\ \mathrm{YU} & = & \text { Yuma bat }\end{array}$

\section{CONFLICT OF INTEREST}

None. This work was supported internally by the Canadian Food Inspection Agency.

\section{ACKNOWLEDGEMENTS}

We thank Alexander Wandeler, former leader of the Rabies Centre of Expertise, for providing the bat specimens employed for this study. We also thank Mary Sheen, Maria Harding, Frances Muldoon, Josephine Kush (ADRILethbridge) and all other staff of the rabies diagnostic group for their technical assistance to this study. Drs. D. Nagorsen and D. McAlpine are acknowledged for their assistance in species identification of some specimens. Parts of this research fulfilled the requirement of an Honours project for $E$. Guerrero co-supervised by J. Basso, Department of Biology, University of Ottawa.

\section{REFERENCES}

[1] Calisher CH, Childs JE, Field HE, Holmes KV, Schountz T. Bats: important reservoir hosts of emerging viruses. Clin Microbiol Rev 2006; 19: 531-45

[2] Hebert PDN, Cywinska A, Ball SL, deWaard JR. Biological identifications through DNA barcodes. Proc Royal Soc London, series B 2003; 270: 313-22.

[3] Hebert PDN, Stoeckle MY, Zemlak TS, Francis CM. Identification of birds through DNA barcodes. PLOS Biol 2004; 2: 1657-63.

[4] Clare EL, Lim BK, Engstrom MD, Eger JL, Hebert PDN. DNA barcoding of neotropical bats: species identification and discovery within Guyana. Mol Ecol Notes 2007; 7: 184-90.

[5] Mayer F, Dietz C, Kiefer A. Molecular species identification boosts bat diversity. Front Zool 2007; 4:4 doi:10.1186/1742-9994-4-4.

[6] International Committee on Taxonomy of Viruses Master Species List 2009 - Version 4. Available from: http://talk.ictvonline.org/ files/ictv documents/m/msl/1231.aspx.
[7] Wunner WH. Rabies virus. In: Jackson AC, Wunner WH, Eds Rabies, $2^{\text {nd }}$ ed. London: Academic Press 2007; pp. 23-68.

[8] Badrane H, Tordo N. Host switching in Lyssavirus history from the Chiroptera to the Carnivora orders. J Virol 2001; 75: 8096-104.

[9] Nadin-Davis SA, Abdel-Malik M, Armstrong J, Wandeler AI. Lyssavirus $\mathrm{P}$ gene characterisation provides insights into the phylogeny of the gene and identifies structural similarities and diversity within the encoded phosphoprotein. Virology 2002; 298: 286-305.

[10] Hughes GJ, Orciari, LA, Rupprecht CE. Evolutionary timescale of rabies virus adaptation to North American bats inferred from the substitution rate of the nucleoprotein gene. J Gen Virol 2005; 86: 1467-74.

[11] Hanlon CA, Niezgoda M, Rupprecht CE. Rabies in Terrestrial Animals. In: Jackson AC, Wunner WH, Eds. Rabies, $2^{\text {nd }}$ ed. London: Academic Press. 2007; pp. 201-58.

[12] Rosatte RC, MacDonald E, Sobey K, et al. The elimination of raccoon rabies from Wolfe Island, Ontario: Animal density and movements. J Wildl Dis 2007; 43: 242-50.

[13] Rosatte RC, Power MJ, Donovan D, et al. Elimination of arctic variant rabies in red foxes, metropolitan Toronto. Emerg Infect Dis 2007; 13: 25-7.

[14] Belotto A, Leanes LF, Schneider MC, Tamayo H, Correa E. Overview of rabies in the Americas. Virus Res 2005; 111: 5-12.

[15] Rupprecht CE, Hanlon CA, Slate D. Control and prevention of rabies in animals: paradigm shifts. Dev Biol (Basel) 2006; 125: 103-11.

[16] Linhart SB, Flores Crespo R, Mitchell GC. Control de murcielagos vampiros por medio de un anticoagulante. Bol Oficina Sanit Panam 1972; 73: 100-9.

[17] Aguilar-Setién A, Campos YL, Cruz ET, Kretschmer R, Brochier B, Pastoret P-P. Vaccination of vampire bats using recombinant Vaccinia-Rabies virus. J Wildl Dis 2002; 38: 539-44.

[18] Almeida MF, Martorelli LFA, Aires CC, Barros RF, Massad E. Vaccinating the vampire bat Desmodus rotundus against rabies. Virus Res 2008; 137: 275-7.

[19] Messenger, SL, Smith JS, Rupprecht CE. Emerging epidemiology of bat-associated cryptic cases of rabies in humans in the United States. Clin Infect Dis 2002; 35: 738-47.

[20] Elmgren LD, Nadin-Davis SA, Muldoon FT, Wandeler AI. Diagnosis and analysis of a recent case of human rabies in Canada. Can J Infect Dis 2002; 13: 129-33.

[21] Johnstone J, Saxinger L, McDermid R et al. Human rabies - Alberta, Canada, 2007. MMWR 2008; 57: 197-200.

[22] Travassos da Rosa ES, Kotait I, Barbosa TF, et al. Bat-transmitted human rabies outbreaks, Brazilian Amazon. Emerg Infect Dis 2006; 12: 1197-202.

[23] Leslie MJ, Messenger S, Rohde RE, et al. Bat-associated rabies virus in skunks. Emerg Infect Dis 2006; 12: 1274-7.

[24] Baer GM, Smith JS. Rabies in nonhematophagus bats. In: Baer GM, Ed. The Natural History of Rabies, $2^{\text {nd }}$ ed. Boca Raton: CRC Press. 1991; pp. 341-66.

[25] Constantine DG. An updated list of rabies-infected bats in North America. J Wildl Dis 1979; 15: 347-9.

[26] Rosatte RC. Bat rabies in Canada: history, epidemiology, and prevention. Can Vet J 1987; 28: 754-6.

[27] Childs JE, Trimarchi CV, Krebs JW. The epidemiology of bat rabies in New York State, 1988-92. Epidemiol Infect 1994; 113: 501-11.

[28] Hester LC, Best TL, Hudson MK. Rabies in bats from Alabama. J Wildl Dis 2007; 43: 291-9.

[29] Rohde RE, Mayes BC, Smith JS, Neill SU. Bat rabies, Texas, 1996-2000. Emerg Infect Dis 2004;10: 948-52.

[30] Mondul AM, Krebs JW, Childs JE. Trends in national surveillance for rabies among bats in the United States (1993-2000). J Am Vet Med Assoc 2003; 222: 633-9.

[31] Franka RD, Constantine G, Kuzmin I, et al. A new phylogenetic lineage of rabies virus associated with western pipistrelle bats (Pipistrellus hesperus). J Gen Virol 2006; 87: 2309-21.

[32] Canadian bats. Available from: http://www.hww.ca/hww2.asp?id= 63.

[33] Smith JS, Orciari LA, Yager PA. Molecular epidemiology of rabies in the United States. Semin Virol 1995; 6: 387-400.

[34] Nadin-Davis SA, Huang W, Armstrong J, et al. Antigenic and genetic divergence of rabies viruses from bat species indigenous to Canada. Virus Res 2001; 74: 139-56. 
[35] Jackson FR, Turmelle AS, Farino DM, Franka R, McCracken GF, Rupprecht CE. Experimental rabies virus infection of big brown bats (Eptesicus fuscus). J Wildl Dis 2008; 44: 612-21.

[36] Nadin-Davis SA, Feng Y, Mousse D, Wandeler AI, Aris-Brosou S. Spatial and temporal dynamics of rabies virus variants in big brown bat populations across Canada: footprints of an emerging zoonosis. Mol Ecol 2010; 19: 2120-36.

[37] Velasco-Villa A, Messenger SL, Orciari LA, et al. Identification of a new rabies virus variant in a Mexican immigrant. Emerg Infect Dis 2008; 12: 1906-8.

[38] National Audubon Society. National Audubon Society Field Guide to North American Mammals. Knopf Doubleday Publishing Group. 1996.

[39] Nagorsen DW. An Identification manual to the small mammals of British Columbia. British Columbia Ministry of Sustainable Resource Management, British Columbia Ministry of Water, Land and Air Protection, Biodiversity Branch and Royal British Columbia Museum. 2002.

[40] Skulls of British Columbia Mammals: bats. Available from: http://capewest.ca/bats.html

[41] Maps of bat species distribution in Canada. Available from: http://canadianbiodiversity.mcgill.ca/english/species/mammals/othe rs.htm\#bats.

[42] Webster WA, Casey GA. Diagnosis of rabies infection. In: Campbell JB, Charlton KM, Eds. Rabies. Boston: Kluwer Academic Publishers 1988; pp. 201-22.

[43] Desloire S, Moro CV, Chauve C, Zenner L. Comparison of four methods of extracting DNA from D. gallinae (Acari: Dermanyssidae). Vet Res 2006; 37: 725-32.

[44] Thompson JD, Gibson TJ, Plewniak F, Jeanmougin F, Higgins DG. The ClustalX windows interface: flexible strategies for multiple sequence alignment aided by quality analysis tools. Nucleic Acids Res 1997; 24: 4876-82.

[45] Tamura K, Dudley J, Nei M, Kumar, S. MEGA4: Molecular Evolutionary Genetics Analysis (MEGA) software version 4.0. Mol Biol Evol 2007; 24: 1596-9.

[46] Felsenstein J. PHYLIP (Phylogeny Inference Package) version 3.6. Distributed by the author. Department of Genome Sciences, University of Washington, Seattle. Available from: http://evolution.genetics.washington.edu/phylip.html

[47] Guindon S, Delsuc F, Dufayard JF, Gascuel O. Estimating maximum likelihood phylogenies with PhyML. Methods Mol Biol 2009; 537: 113-37.
[48] Posada D, Crandall KA. Modeltest: testing the model of DNA substitution. Bioinformatics 1998;14: 817-8.

[49] BioEdit version 7.0.5. Available from: http://www.mbio.ncsu.edu/ BioEdit/page2.html.

[50] Barcode of life database. Available from: http://www.boldsystems.org/views/login.php

[51] Frézal L, Leblois R. Four years of DNA barcoding: Current advances and prospects. Infect Genet Evol 2008: 8: 727-736.

[52] Harris SL, Johnson N, Brookes SM, Hutson AM, Fooks AR, Jones G. The application of genetic markers for EBLV surveillance in European bat species. Dev Biol (Basel) 2008; 131: 347-63.

[53] Carnieli Jr P, de Oliveira Fahl W, Castilho JG, Brandão PE, Carrieri, ML, Kotait I. Species determination of Brazilian mammals implicated in the epidemiology of rabies based on the control region of mitochondrial DNA. 2008; Braz J Infect Dis 12: 462-5.

[54] Bertolazzi P, Felici G, Weitschek E. Learning to classify species with barcodes. BMC Bioinformatics 2009; 10 (Suppl 14):S7.

[55] Government of Canada Species at Risk Public Registry. Available from: http://www.sararegistry.gc.ca

[56] Streicker DG, Turmelle AS, Vonhof MJ, Kuzmin IV, McCracken GF, Rupprecht CE. Host phylogeny constrains cross-species emergence and establishment of rabies virus in bats. Science 2010; 329: 676-9.

[57] Stadelmann B, Lin L-K, Kunz TH, Ruedi M. Molecular phylogeny of New World Myotis (Chiroptera,Vespertilionidae) inferred from mitochondrial and nuclear DNA genes. Mol Phyl Evol 2007; 43: $32-48$.

[58] Tobe SS, Kitchener ACX, Linacre AMT. Reconstructing mammalian phylogenies: a detailed comparison of the cytochrome $b$ and cytochrome oxidase subunit 1 mitochondrial genes. PLOS One 2010; 5(11): e14156.

[59] Kurta A, Baker RH. Eptesicus fuscus. Mammalian species 1990; 356: $1-10$.

[60] Hajibabaei M, Singer, GAC, Clare EL, Hebert PDN. Design and applicability of DNA arrays and DNA barcodes in biodiversity monitoring. BMC Biol 2007; 5: 24.

[61] Kobayashi Y, Sato G, Kato M, et al. Genetic diversity of bat rabies viruses in Brazil. Arch Virol 2007; 152: 1995-2004

[62] Sodré MM, da Gama AR, de Almeida MF. Updated list of bat species positive for rabies in Brazil. Rev Inst Med Trop Sao Paulo. 2010; 52: 75-81.

(C) Nadin-Davis et al.; Licensee Bentham Open.

This is an open access article licensed under the terms of the Creative Commons Attribution Non-Commercial License (http://creativecommons.org/licenses/by-nc/3.0/) which permits unrestricted, non-commercial use, distribution and reproduction in any medium, provided the work is properly cited. 